Open Access

\title{
The relationship between epicardial fat tissue thickness and visceral adipose tissue in lean patients with polycystic ovary syndrome
}

\author{
Dilek Arpaci ${ }^{1 *}$, Aysel Gurkan Tocoglu², Sabiye Yilmaz ${ }^{3}$, Hasan Ergenc ${ }^{2}$, Ali Tamer $^{2}$, Nurgul Keser ${ }^{3}$
} and Huseyin Gunduz ${ }^{3}$

\begin{abstract}
Background: Polycystic ovary syndrome (PCOS) is related to metabolic syndrome, insulin resistance, and cardiovascular metabolic syndromes. This is particularly true for individuals with central and abdominal obesity because visceral abdominal adipose tissue (VAAT) and epicardial adipose tissue (EAT) produce a large number of proinflammatory and proatherogenic cytokines. The present study aimed to determine whether there are changes in VAAT and EAT levels which were considered as indirect predictors for subclinical atherosclerosis in lean patients with PCOS.

Methods: The clinical and demographic characteristics of 35 patients with PCOS and 38 healthy control subjects were recorded for the present study. Additionally, the serum levels of various biochemical parameters were measured and EAT levels were assessed using 2D-transthoracic echocardiography.

Results: There were no significant differences in mean age $(p=0.056)$ or mean body mass index (BMI) $(p=0.446)$ between the patient and control groups. However, the body fat percentage, waist-to-hip ratio, amount of abdominal subcutaneous adipose tissue, and VAAT thickness were higher in the PCOS patient group than in the control group. The amounts of EAT in the patient and control groups were similar $(p=0.384)$. EAT was correlated with BMI, fat mass, waist circumference, and hip circumference but not with any biochemical metabolic parameters including the homeostasis model assessment of insulin resistance index or the levels of triglycerides, low-density lipoprotein cholesterol, and high-density lipoprotein (HDL) cholesterol. However, there was a small positive correlation between the amounts of VAAT and EAT. VAAT was directly correlated with body fat parameters such as BMI, fat mass, and abdominal subcutaneous adipose thickness and inversely correlated with the HDL cholesterol level.

Conclusions: The present study found that increased abdominal adipose tissue in patients with PCOS was associated with atherosclerosis. Additionally, EAT may aid in the determination of the risk of atherosclerosis in patients with PCOS because it is easily measured.
\end{abstract}

Keywords: Polycystic, Ovary, Epicardial, Adipose

\footnotetext{
*Correspondence: drarpaci@gmail.com

'Division of Endocrinology and Metabolism, Department of Internal Medicine, Faculty of Medicine, Bulent Ecevit University, Zonguldak, Turkey Full list of author information is available at the end of the article
} 


\section{Background}

Polycystic ovary syndrome (PCOS) is a heterogeneous disease that affects 5 to $10 \%$ of women in the reproductive period [1]. Many studies have shown that PCOS is associated with various cardiovascular risk factors such as obesity, insulin resistance, hyperlipidemia, metabolic syndrome, and hypertension [1-3]. Additionally, patients with PCOS have a high incidence of central and abdominal obesity and marked increases in the waist circumference (WC) and waist-to-hip ratio (WHR) $[4,5]$.

Visceral abdominal adipose tissue (VAAT) surrounds the internal organs, and increased amounts of VAAT are more important than increased levels of subcutaneous fat in terms of the risks of metabolic syndrome, insulin resistance, and cardiovascular mortality [6]. Epicardial adipose tissue (EAT) and visceral adipose tissue (VAT), located between the myocardium and visceral epicardium, respectively, are derived from the same origin [7]. This is important because both of these body fat tissues produce large numbers of proinflammatory and proatherogenic cytokines $[8,9]$. The reported findings regarding abdominal fat tissue and EAT in patients with PCOS are controversial [8-21]. For example, patients with PCOS have been shown to have increased [10-14], similar [15-17], or decreased [18] amounts of abdominal fat. Similarly, the amount of EAT in patients with PCOS has been reported to be increased and unchanged compared with healthy control groups [19-21]. However, not all patients with PCOS are obese; in fact, a 2001 study of 346 patients with PCOS found that $56 \%$ of such patients are lean [22]; $56.0 \%$ had a body mass index (BMI) of $<25 \mathrm{~kg} / \mathrm{m}^{2}, 11.3 \%$ had a BMI of 25 to $27 \mathrm{~kg} / \mathrm{m}^{2}$, and $32.7 \%$ had a BMI of $\geq 27 \mathrm{~kg} / \mathrm{m}^{2}$ [22]. Thus, the present study aimed to determine whether there are changes in the amounts of VAAT and EAT in lean patients with PCOS compared with healthy control subjects.

\section{Methods}

\section{Selection of subjects}

The present study included 38 healthy control subjects and 35 patients with PCOS and concurrent hyperandrogenism and/or ovulatory dysfunction who were admitted to the Endocrinology and Metabolism Department of Sakarya Training and Research Hospital at Sakarya University from January 2013 to June 2014. Some of these patients were diagnosed by a gynecologist, and some were diagnosed by the present authors based on the presence of two of the three criteria from the Rotterdam European Society for Human Reproduction and Embryology/American Society for Reproductive Medicine (ESHRE/ASRM) for PCOS: a) oligomenorrhea, amenorrhea, or anovulation; b) the presence of clinical or biochemical hyperandrogenism; and/or c) the presence of polycystic ovaries as determined by a pelvic ultrasound [22]. The control group comprised healthy secretaries, nurses, and doctors from our hospital who volunteered for the study and had regular menstrual cycles, normal androgen levels, the absence of hirsutism, and no polycystic ovary as determined by a pelvic ultrasound. The demographic data of the patient and control groups were recorded. The present study was approved by the Sakarya University Faculty of Medicine Ethics Committee (Date: 24.02.2014; No. 27), and all participants provided written informed consent.

\section{Exclusion criteria}

Subjects were excluded from the present study if they had history of smoking, diabetes, or hypertension; had been diagnosed with Cushing's syndrome (based on the 1-mg dexamethasone suppression test) or non-classic congenital adrenal hyperplasia (based on a $17-\mathrm{OH}$ progesterone level of $>10 \mathrm{ng} / \mathrm{dL}$ after stimulation); exhibited cardiac disease; and/or had used antidiabetic, antihypertensive, antilipidemic, or oral contraceptive drugs within the past 3 months.

\section{Measurements}

The height and weight of all subjects were measured, and their BMI was calculated as the weight in kilograms divided by the square of height in meters. WC was measured from the narrowest part of the body between the iliac crest and the rib, and hip circumference $(\mathrm{HC})$ was measured at the widest part of the hips. The WHR was calculated as the ratio of WC to $\mathrm{HC}$ [21].

\section{Body composition analysis}

The basal metabolic rate, body fat percentage, and total body water of each patient were evaluated with a Tanita Body Composition Analyzer (Model TBF-300; Tanita Corporation, Itabashi-ku, Tokyo, Japan) while the patient was in a standing position without shoes and with light clothing on after a $\geq 8$-h fast with sufficient hydration. Abdominal subcutaneous fat tissue thickness and visceral abdominal fat tissue thickness were recorded using bioelectrical impedance with the Tanita Abdominal Fat Analyzer (AB-140 Viscan; Tanita Corporation, Tokyo, Japan). The blood pressure of each patient was assessed after at least $10 \mathrm{~min}$ of rest with a sphygmomanometer (ERKA; Bad Tölz, Germany); two measurements were performed, and the average of the blood pressure measurements was calculated [23].

\section{Biochemical analysis}

Blood samples were obtained from the patients in the morning after at least $8 \mathrm{~h}$ of fasting. The fasting plasma glucose (FPG) and fasting insulin levels of the patients were measured, and the homeostatic model assessmentinsulin resistance (HOMA-IR) index was calculated using 
the following formula: (FPG $[\mathrm{mg} / \mathrm{dL}] \times$ fasting plasma insulin $[\mu \mathrm{IU} / \mathrm{mL}] / 405)$. If the HOMA-IR index was $>2.7$, insulin resistance was considered to be present [24]. Serum lipid levels of low-density lipoprotein (LDL) cholesterol, high-density lipoprotein (HDL) cholesterol, and triglycerides (TG) were measured using xylidine blue with an end-point colorimetric method (Roche Diagnostics GmbH; Mannheim, Germany). FPG levels were measured with a hexokinase method (Roche Diagnostics $\mathrm{GmbH}$ ).

\section{Echocardiography}

All patients were directed to the Department of Cardiology at Sakarya Training and Research Hospital, and the EAT thickness was measured using 2D-transthoracic echocardiography by the same cardiologist. The parasternal long- and short-axis images of EAT, which allow for the most accurate measurement from the right ventricle, were obtained using a standard parasternal image in the left lateral decubitus position. EAT was defined as the echo-free space between the outer wall of the myocardium and the visceral layer of pericardium at endsystole in the right ventricle [25].

\section{Statistical analysis}

All statistical analyses were performed with SPSS software, version 15 (SPSS, Inc., Chicago, IL, USA). Nonparametric tests were utilized due to the prevalence of variables. The Mann-Whitney $U$ test was applied to assess differences between groups, and Spearman's test was applied to assess correlations between the variables. A $p$ value of $<0.05$ was considered to indicate statistical significance, and a correlation was considered to be present if Spearman's value was $\geq 0.50$. Continuous variables are expressed as either the mean \pm standard deviation (SD) or the median (minimum-maximum), and categorical variables are expressed as either frequency or percentage. Continuous variables were compared with an independent-samples t-tests or the Mann-Whitney $U$ test, and categorical variables were compared using Pearson's chi-square test. A $p$ value of $<0.05$ was considered to indicate statistical significance for all tests.

\section{Results}

The body fat distribution, total body water, WC, HC, WHR, amount of abdominal subcutaneous adipose tissue, VAAT thickness, blood pressure, and levels of LDL cholesterol, HDL cholesterol, are TG are provided in Table 1. There were no significant differences in the mean age $(p=0.056)$ or mean BMI $(p=0.446)$ between the patient and control groups, but the body fat percentage, WHR, amount of abdominal subcutaneous adipose tissue, and VAAT thickness were higher in the patient group. However, the patient and control groups had similar amounts of EAT $(p=0.384)$ (Table 1$)$.

Table 1 Comparison of demographic, body analysis and laboratory parameters of the patient and the control group

\begin{tabular}{|c|c|c|c|}
\hline Feature & Patients $(n=35)$ & Controls $(n=38)$ & $P$ value \\
\hline Age (years) & $25.16 \pm 4.12$ & $27.44 \pm 4.31$ & 0.056 \\
\hline $\mathrm{BMI}\left(\mathrm{kg} / \mathrm{m}^{2}\right)$ & $25.60 \pm 5.22$ & $23.67 \pm 3.70$ & 0.404 \\
\hline Fat mass (\%) & $31.74 \pm 10.12$ & $26.33 \pm 7.61$ & 0.042 \\
\hline Total body water (kg) & $34.11 \pm 4.48$ & $32.72 \pm 2.33$ & 0.193 \\
\hline Waist circumference $(\mathrm{cm})$ & $91.76 \pm 18.95$ & $86.50 \pm 9.71$ & 0.677 \\
\hline Hip circumference $(\mathrm{cm})$ & $103.56 \pm 15.27$ & $100.55 \pm 7.48$ & 0.557 \\
\hline WHR & $0.94 \pm 0.06$ & $0.89 \pm 0.04$ & 0.007 \\
\hline VAAT thickness & $9.24 \pm 4.67$ & $6.77 \pm 2.68$ & 0.042 \\
\hline Abdominal subcutaneous adipose tissue thickness & $40.48 \pm 8.83$ & $32.86 \pm 9.48$ & 0.008 \\
\hline Systolic blood pressure (mmHg) & $120.10 \pm 7.78$ & $120.28 \pm 7.28$ & 0.979 \\
\hline Diastolic blood pressure (mmHg) & $70.26 \pm 7.40$ & $72.76 \pm 9.21$ & 0.318 \\
\hline $\mathrm{FPG}(\mathrm{mg} / \mathrm{dL})$ & $89.16 \pm 9.12$ & $87.72 \pm 7.92$ & 0.565 \\
\hline Insulin ( $\mu \mid \mathrm{U} / \mathrm{mL})$ & $9.77 \pm 6.27$ & $6.80 \pm 3.45$ & 0.073 \\
\hline HOMA-IR & $2.13 \pm 1.33$ & $1.60 \pm 0.67$ & 0.082 \\
\hline $\mathrm{TG}(\mathrm{mg} / \mathrm{dL})$ & $11.52 \pm 53.81$ & $85.52 \pm 31.49$ & 0.058 \\
\hline $\mathrm{LDL}(\mathrm{mg} / \mathrm{dL})$ & $106.40 \pm 35.57$ & $96.38 \pm 28.73$ & 0.305 \\
\hline $\mathrm{HDL}(\mathrm{mg} / \mathrm{dL})$ & $55.69 \pm 16.25$ & $58.90 \pm 11.96$ & 0.300 \\
\hline EAT (mm) & $4.72 \pm 0.88$ & $4.43 \pm 1.31$ & 0.384 \\
\hline
\end{tabular}

BMI body mass index, VAAT visceral abdominal adipose tissue, FPG fasting plasma glucose, HOMA-IR Homeostatic Model Assessment-insulin resistance, TG triglyceride, LDL low density lipoprotein, $H D L$ high density lipoprotein, EAT epicardial adipose tissue. Continuous variables were compared with an independent-samples t-tests or the Mann-Whitney $U$ test, and categorical variables were compared using Pearson's chi-square test. A $p$ value of $<0.05$ was considered to indicate statistical significance for all tests 
EAT had a significantly positive correlation with BMI $(\mathrm{r}=0.260, p=0.034)$, fat mass $(\mathrm{r}=0.250, p=0.041)$, WC $(\mathrm{r}=0.301, p=0.016)$, and abdominal circumference $(\mathrm{r}=$ $0.254, p=0.043)$, but it was not correlated with the HOMA-IR index or the levels of TG, LDL cholesterol, or HDL cholesterol $(p>0.05)$ (Table 2). There was a small positive correlation between VAAT and EAT $(\mathrm{r}=$ $0.248, p=0.048)$. VAAT was also directly associated with BMI $(\mathrm{r}=0.921, p<0.01)$, fat mass $(\mathrm{r}=0.941, p<0.01)$, WC $(\mathrm{r}=0.941, p<0.01)$, HC ( $\mathrm{r}=0.876, p<0.01)$, abdominal subcutaneous adipose thickness $(\mathrm{r}=0.896, p<0.01)$, the HOMA-IR index $(\mathrm{r}=0.618, p<0.01)$, and the levels of TG $(\mathrm{r}=0.388, p<0.01)$ and LDL cholesterol $(\mathrm{r}=0.288, p=$ $0.016)$. Conversely, VAAT was inversely associated with the HDL cholesterol level $(r=-0.488, p<0.01)$ (Table 3$)$.

\section{Discussion}

Although the patient and control groups in the present study had similar ages and BMIs, the lean patients with PCOS exhibited a higher WHR, VAAT, and abdominal subcutaneous fat tissue thickness than did the control group. In contrast, there were no significant differences in EAT. However, EAT was significantly correlated with VAAT, BMI, fat mass, WC, and HC.

Previous studies have shown a positive correlation between EAT thickness and VAAT thickness [26-28] independent of obesity [26,27], and this correlation seems to be more important than WC [28]. Although there is an increased amount of EAT in obese patients with than without PCOS [19-21], EAT is not different between lean patients with PCOS and the normal population $[21,29]$. Similarly, the present study found no differences in EAT between the two groups. Compared with normal individuals, patients with PCOS exhibit increases in total fat mass and organ-specific VAT [29]. Furthermore, these increases are positively correlated with both systolic and diastolic blood pressure and the levels of

Table 2 Correlation analysis between EAT and variables

\begin{tabular}{lcc}
\hline Variable & r value & $p$ value \\
\hline BMI $\left(\mathrm{kg} / \mathrm{m}^{2}\right)$ & 0.260 & $\mathbf{0 . 0 3 4}$ \\
Fat mass (\%) & 0.250 & $\mathbf{0 . 0 4 1}$ \\
Waist circumference $(\mathrm{cm})$ & 0.301 & $\mathbf{0 . 0 1 6}$ \\
Hip circumference $(\mathrm{cm})$ & 0.254 & $\mathbf{0 . 0 4 3}$ \\
HOMA-IR & 0.119 & 0.490 \\
TG (mg/dL) & 0.076 & 0.550 \\
LDL (mg/dL) & 0.158 & 0.209 \\
HDL (mg/dL) & -0.185 & 0.141 \\
\hline
\end{tabular}

BMI body mass index, HOMA-IR Homeostatic Model Assessment-insulin resistance, $T G$ triglyceride, $L D L$ low density lipoprotein, HDL high density lipoprotein, $E A T$ epicardial adipose tissue. Continuous variables were compared with an independent-samples t-tests or the Mann-Whitney $U$ test, and categorical variables were compared using Pearson's chi-square test. A $p$ value of $<0.05$ was considered to indicate statistical significance for all tests
Table 3 Correlation analysis between VAAT and variables

\begin{tabular}{lcc}
\hline Variable & r value & $P$ value \\
\hline EAT $(\mathrm{mm})$ & 0.248 & $\mathbf{0 . 0 4 8}$ \\
BMI $\left(\mathrm{kg} / \mathrm{m}^{2}\right)$ & 0.921 & $<0.01$ \\
Fat mass $(\%)$ & 0.941 & $<0.01$ \\
Waist circumference $(\mathrm{cm})$ & 0.941 & $<0.01$ \\
Hip circumference $(\mathrm{cm})$ & 0.876 & $<0.01$ \\
Abdominal subcutaneous adipose tissue thickness & 0.896 & $<0.01$ \\
HOMA-IR & 0.618 & $<0.01$ \\
TG $(\mathrm{mg} / \mathrm{dL})$ & 0.388 & $<0.01$ \\
LDL $(\mathrm{mg} / \mathrm{dL})$ & 0.288 & $\mathbf{0 . 0 1 6}$ \\
HDL $(\mathrm{mg} / \mathrm{dL})$ & -0.488 & $<0.01$ \\
\hline
\end{tabular}

BMI body mass index, HOMA-IR Homeostatic Model Assessment-insulin resistance, $T G$ triglyceride, $L D L$ low density lipoprotein, $H D L$ high density lipoprotein, $E A T$ epicardial adipose tissue. Continuous variables were compared with an independent-samples t-tests or the Mann-Whitney $U$ test, and categorical variables were compared using Pearson's chi-square test. A $p$ value of $<0.05$ was considered to indicate statistical significance for all tests

fasting glucose, insulin, LDL cholesterol, TG, and transaminases but negatively correlated with the insulin sensitivity index and HDL cholesterol. Likewise, the present study found that fat mass, abdominal subcutaneous adipose tissue, and VAAT thickness were higher in the patient group than in the control group. Additionally, VAAT thickness was positively correlated with BMI, fat mass, WC, HC, abdominal subcutaneous adipose tissue thickness, and the levels of TG and LDL cholesterol but negatively correlated with HDL cholesterol.

Sahin et al. [21] reported that EAT is positively correlated with age, BMI, WC, the glucose level, the HOMAIR index, and the TG level. Similarly, the present study found that EAT was positively correlated with BMI, WC, $\mathrm{HC}$, and VAAT; however, in contrast to those previous findings, EAT was not correlated with fasting glucose, the HOMA-IR index, or the lipid parameters. This may be due to the fact that the patients with PCOS in the present study were lean rather than obese. Another study found that EAT is correlated with BMI, WC, VAT thickness, and insulin resistance [30]. In the present study, EAT was positively correlated with BMI, WC, and VAAT but not with the HOMA-IR index. EAT is reportedly more closely associated with VAT than with total body fat $[28,30]$.

In studies employing magnetic resonance imaging (MRI), the abdominal adipose tissue thicknesses of patients with PCOS and normal control subjects did not significantly differ [16, 31-33]. It has also been shown that VAAT thickness is increased only in mildly obese patients with PCOS relative to control subjects [15] and that obesity predicts insulin resistance independently of PCOS [31]. Furthermore, a study conducted using a bioimpedance device found that there was less VAT in lean patients with PCOS than in the control group [18]. 
In contrast, the present study found greater VAAT thickness in lean patients with PCOS than in the control group despite the fact that the EAT thickness did not change.

The gold standard tests for measuring VAT are MRI and computed tomography (CT) [34]. Thus, a limitation of the present study may be that the amounts of abdominal subcutaneous adipose tissue and VAT were assessed using bioelectrical impedance. However, it is difficult to measure adipose tissue using CT or MRI because of cost-effectiveness, the application of radiation, and the use of contrast media. Additionally, previous studies have shown that the results of bioelectrical impedance tests and CT scans when measuring VAT are closely correlated [35]. Consequently, given that the present study found a small positive correlation between EAT thickness and VAAT thickness, echocardiography would appear to be an easy, simple, noninvasive, reliable, and accessible method for the measurement of these parameters relative to the use of MRI scans [25]. EAT is important for the determination of both VAAT thickness and cardiovascular risk [26, 36], and increased abdominal adipose tissue is related to an increased risk of atherosclerosis [37] and mortality [38]. Because it can be difficult to measure abdominal adipose tissue, it may be more economical and efficient to determine these risk factors by measuring EAT.

\section{Conclusions}

The present study observed several associations between EAT thickness and cardiovascular risk in patients with PCOS. Because of the difficulties related to the measurement of abdominal adipose tissue thickness, the assessment of EAT may be a relatively easy-to-use but important tool for the determination of cardiovascular risk.

\section{Abbreviations}

PCOS: Polycystic ovary syndrome; VAAT: Visceral abdominal adipose tissue; EAT: Epicardial adipose tissue; BMI: Body mass index.

\section{Competing interest}

All authors declare that there were no conflict of interest or any funding source.

\section{Authors' contributions \\ DA, AGT and SY contributed to conception and design, acquisition, analysis and interpretation of data and drafting the article. HE, AT, NK, HG carried out all the experiments described in the manuscripts. DA, SY, AT and HG contributed to conception, analysis and interpretation of data and reviewed the article critically for important intellectual content. All authors read and approved the final manuscript.}

\footnotetext{
Author details

${ }^{1}$ Division of Endocrinology and Metabolism, Department of Internal Medicine, Faculty of Medicine, Bulent Ecevit University, Zonguldak, Turkey. ${ }^{2}$ Department of Internal Medicine, Faculty of Medicine, Sakarya University Training and Research Hospital, Sakarya, Turkey. ${ }^{3}$ Department of Cardiology, Sakarya University Training and Research Hospital, Sakarya, Turkey.
}

Received: 5 August 2015 Accepted: 14 October 2015

Published online: 06 November 2015

\section{References}

1. Diamanti-Kandarakis E. Role of obesity and adiposity in polycystic ovary syndrome. Int J Obes (Lond). 2007;31:8-13.

2. Schroder AK, Tauchert S, Ortmann O, Diedrıch K, Weiss JM. Insulin resistance in patients with polycystic ovary syndrome. Ann Med. 2004;36:426-39.

3. Chen MJ, Yang WS, Yang JH, Chen CL, Ho HN, Yang YS. Relationship between androgen levels and blood pressure in young women with polycystic ovary syndrome. Hypertension. 2007:49:1442-7.

4. Escobar-Morreale HF, San Millan JL. Abdominal adiposity and the polycystic ovary syndrome. Trends Endocrinol Metab. 2007;18:266-72.

5. Pasquali R, Casimirri F, Cantobelli S, Labate AM, Venturoli S, Paradisi R, et al. Insulin and androgen relationships with abdominal body fat distribution in women with and without hyperandrogenism. Horm Res. 1993;39:179-87.

6. Goodpaster BH, Krishnaswami S, Harris TB, Katsiaras A, Kritchevsky SB, Simonsick EM, et al. Obesity, regional body fat distribution, and the metabolic syndrome in older men and women. Arch Intern Med. 2005;165:777-83.

7. Sacks HS, Fain JN. Human epicardial adipose tissue: a review. Am Heart J. 2007;153:907-17.

8. lacobellis $\mathrm{G}$, Barbaro $\mathrm{G}$. The double role of epicardial adipose tissue as pro-and anti-inflammatory organ. Horm Metab Res. 2008;40:442-5.

9. lacobellis $\mathrm{G}$. Is obesity a risk factor for atrial fibrillation? Nat Clin Pract Cardiovasc. 2005;2:134-5.

10. Hutchison SK, Stepto NK, Harrison CL, Moran LJ, Strauss BJ, Teede HJ. Effects of exercise on insulin resistance and body composition in overweight and obese women with and without polycystic ovary syndrome. J Clin Endocrinol Metab. 2011;96:48-56.

11. Battaglia C, Battaglia B, Mancini F, Paradisi R, Fabbri R, Venturoli S. Ultrasonographic extended-view technique for evaluation of abdominal fat distribution in lean women with polycystic ovary syndrome. Acta Obstet Gynecol Scand. 2011;90:600-8.

12. Jones H, Sprung VS, Pugh CJ, Daousi C, Irwin A, Aziz N, et al. Polycystic ovary syndrome with hyperandrogenism is characterized by an increased risk of hepatic steatosis, compared to nonhyperandrogenic PCOS phenotypes and healthy controls, independent of obesity and insulin resistance. J Clin Endocrinol Metab. 2012;97:3709-16.

13. Cascella T, Palomba S, De Sio I, Manguso F, Giallauria F, De Simone B, et al. Visceral fat is associated with cardiovascular risk inwomenwith polycystic ovary syndrome. Hum Reprod. 2008;23:153-9.

14. Karabulut A, Yaylali GF, Demirlenk S, Sevket O, Acun A. Evaluation of body fat distribution inPCOSand its association with carotid atherosclerosis and insulin resistance. Gynecol Endocrinol. 2012;28:111-4.

15. Barber TM, Golding SJ, Alvey C, Wass JA, Karpe F, Franks S, et al. Global adiposity rather than abnormal regional fat distribution characterizes women with polycystic ovary syndrome. J Clin Endocrinol Metab. 2008;93:999-1004

16. Mannerås-Holm L, Leonhardt H, Kullberg J, Jennische E, Odén A, Holm G, et al. Adipose tissue has aberrant morphology and function in PCOS: enlarged adipocytes and low serum adiponectin, but not circulating sex steroids, are strongly associated with insulin resistance. J Clin Endocrinol Metab. 2011;96:304-11.

17. Penaforte FR, Japur CC, Diez-Garcia RW, Chiarello PG. Upper trunk fat assessment and its relationship with metabolic and biochemical variables and body fat in polycystic ovary syndrome. J Hum Nutr Diet. 2011;24:39-46.

18. Dolfing JG, Stassen CM, van Haard PM, Wolffenbuttel BH, Schweitzer DH. Comparison of MRI-assessed body fat content between lean women with polycystic ovary syndrome (PCOS) and matched controls: less visceral fat with PCOS. Hum Reprod. 2011;26:1495-500.

19. Cakir E, Doğan M, Topaloglu O, Ozbek M, Cakal E, Vural MG, et al. Subclinical atherosclerosis and hyperandrogenemia are independent risk factors for increased epicardial fat thickness in patients with PCOS and idiopathic hirsutism. Atherosclerosis. 2013;226:291-5.

20. Aydogdu A, Uckaya G, Tasci I, Baysan O, Tapan S, Bugan B, et al. The relationship of epicardial adipose tissue thickness to clinical and biochemical features in women with polycystic ovary syndrome. Endocr J. 2012;59(6):509-16. 
21. Sahin SB, Cure MC, Ugurlu Y, Ergul E, Gur EU, Alyildiz N, et al. Epicardial adipose tissue thickness and NGAL levels in women with polycystic ovary syndrome. J Ovarian Res. 2014;7:24.

22. Rotterdam ESHRE/ASRM-Sponsored PCOS Consensus Workshop Group. Revised 2003 consensus on diagnostic criteria and long-term health risks related to polycystic ovary syndrome. Fertil Steril. 2004;81:19-25.

23. Amariles P, Sabater-Hernández D, García-Jiménez E, Rodríguez-Chamorro MÁ, Prats-Más R, Marín-Magán F, et al. Effectiveness of Dader Method for pharmaceutical care on control of blood pressure and total cholesterol in outpatients with cardiovascular disease or cardiovascular risk: EMDADER-CV randomized controlled trial. J Manag Care Pharm. 2012;18(4):311-23.

24. Gokcel A, Ozsahin AK, Sezgin N, Karakose H, Ertorer ME, Akbaba M, et al. High prevalence of diabetes in Adana, a southern province of Turkey. Diabetes Care. 2003;26:3031-4.

25. lacobellis G, Assael F, Ribaudo MC, Zappaterreno A, Alessi G, Di Mario U, et al. Epicardial fat from echocardiography: a new method for visceral adipose tissue prediction. Obes Res. 2003;11:304-10.

26. lacobellis G, Ribaudo MC, Assael F, Vecci E, Tiberti C, Zappaterreno A, et al. Echocardiographic epicardial adipose tissue is related to anthropometric and clinical parameters of metabolic syndrome: a new indicator of cardiovascular risk. J Clin Endocrinol Metab. 2003;88:5163-8.

27. lacobellis G, Leonetti F, Di Mario U. Images in cardiology: massive epicardial adipose tissue indicating severe visceral obesity. Clin Cardiol. 2003;26:237.

28. Singh $\mathrm{N}$, Singh $\mathrm{H}$, Khanijoun HK, lacobellis $\mathrm{G}$. Echocardiographic assessment of epicardial adipose tissue-a marker of visceral adiposity. McGill J Med. 2007;10:26-30.

29. Borruel S, Fernández-Durán E, Alpañés M, Martí D, Alvarez-Blasco F, Luque-Ramírez M, et al. Global adiposity and thickness of intraperitoneal and mesenteric adipose tissue depots are increased in women with polycystic ovary syndrome (PCOS). J Clin Endocrinol Metab. 2013;98(3):1254-63.

30. Fernández Muñoz MJ, Basurto Acevedo L, Córdova Pérez N, Vázquez Martínez AL, Tepach Gutiérrez N, Vega García S, et al. Epicardial adipose tissue is associated with visceral fat, metabolic syndrome, and insulin resistance in menopausal women. Rev Esp Cardiol (Engl Ed). 2014;67(6):436-41.

31. Morin-Papunen LC, Vauhkonen I, Koivunen RM, Ruokonen A, Tapanainen JS. Insulin sensitivity, insulin secretion, and metabolic and hormonal parameters in healthy women and women with polycystic ovarian syndrome. Hum Reprod. 2000;15:1266-74

32. Dunaif A, Segal KR, Futterweit W, Dobrjansky A. Profound peripheral insulin resistance, independent of obesity, in polycystic ovary syndrome. Diabetes. 1989;38:1165-74

33. Diamanti-Kandarakis E, Mitrakou A, Hennes MM, Platanissiotis D, Kaklas N, Spina J, et al. Insulin sensitivity and antiandrogenic therapy in women with polycystic ovary syndrome. Metabolism. 1995;44:525-31.

34. lacobellis G, Sharma AM. Epicardial adipose tissue as new cardio-metabolic risk marker and poten tial therapeutic target in the metabolic syndrome. Curr Pharm Des. 2007;13:2180-4.

35. Nagai M, Komiya H, Mori Y, Ohta T, Kasahara Y, Ikeda Y. Estimating visceral fat area by multifrequency biolectrical impedance. Diabetes Care. 2010;33:1077-9.

36. Taguchi R, Takasu J, Itani Y, Yamamoto R, Yokoyama K, Watanabe S, et al. Pericardial fat accumulation in men as a risk factor for coronary artery disease. Atherosclerosis. 2001;157:203-9.

37. Gasteyger C, Tremblay A. Metabolic impact of body Fat distribution. J Endocrinol Invest. 2002;25:876-83.

38. Dagenais GR, Yi Q, Mann JF, Bosch J, Pogue J, Yusuf S. Prognostic impact of body weight and abdominal obesity in women and men with cardiovascular disease. Am Heart J. 2005;149:54-60.

\section{Submit your next manuscript to BioMed Central and take full advantage of:}

- Convenient online submission

- Thorough peer review

- No space constraints or color figure charges

- Immediate publication on acceptance

- Inclusion in PubMed, CAS, Scopus and Google Scholar

- Research which is freely available for redistribution

Submit your manuscript at www.biomedcentral.com/submit 